\title{
Struktur Rantai Pasok pada Klaster Sayuran untuk Tujuan Pasar Terstruktur
}

\author{
Dias Cakra Supriatna ${ }^{1 *}$, Tomy Perdana ${ }^{2}$, dan Trisna Insan Noor ${ }^{2}$ \\ ${ }^{1}$ Alumni Departemen Agribisnis, Fakultas Pertanian, Universitas Padjadjaran \\ ${ }^{2}$ Departemen Agribisnis, Fakultas Pertanian, Universitas Padjadjaran \\ Jl. Raya Bandung-Sumedang KM 21 Jatinangor 40600 \\ *Alamat korespondensi: dias.cakra@gmail.com
}

\section{ABSTRACT \\ Structure of Supply Chain Cluster Vegetables for the Purpose of Structure Market}

Logistics management vegetable products require special treatment due to the characteristics of vegetables that are easily damaged by physic and biologically. On the other hand, the market demand for fresh produce continues to demand that the product can reach the consumer in a high quality and market demands continuous supply. The purpose of this study was to develop the structure of supply chain logistics system that is optimal on a cluster of high value crops which manages six commodities of main vegetable including tomatoes tw, red peppers, yellow, green, orange and potatoes from farmers producers scattered in eight villages in the District Pangalengan for structured market destination. All commodities delivered every day, on the quality and quantities have been determined by the terms of harvest, post-harvest management and delivery in one day. This study used a qualitative research design. Through this method, a systematic overview of the raised issues was made. A qualitative approach in this study was based on the consideration that the research requires in-depth information (exploratory) from several sources. Research method used was a case study. The results of the study showed the structure of the supply chain in the logistic system cluster of high value crops. A structur supply chain is successful when an effective and efficient system is created so that provide benefits to all actors in the cluster vegetables.

Keywords: Supply chain structure, Cluster vegetables, Vegetable commodity cluster, Agricultural logistic system

\begin{abstract}
ABSTRAK
Manajemen logistik produk sayuran membutuhkan perlakuan khusus dikarenakan karakteristik sayuran yang bersifat mudah rusak secara fisik maupun secara biologis. Disisi lain, permintaan pasar pada produk segar terus menuntut agar produk dapat sampai ke konsumen dalam kualitas yang tinggi dan pasar menuntut pasokan yang kontinyu. Tujuan penelitian ini adalah mengembangkan struktur rantai pasok sistem logistik yang optimal pada Klaster Sayuran Bernilai Tinggi yang mengelola 6 komoditas sayuran utama diantaranya tomat tw, paprika merah, kuning, hijau, oranye dan kentang berasal dari petani produsen yang tersebar dalam 8 Desa di Kecamatan Pangalengan untuk tujuan pasar terstruktur. Seluruh komoditas dikirimkan setiap hari, pada kualitas dan kuantitas yang telah ditentukan dengan syarat waktu panen, pengelolaan pasca panen dan pengiriman dalam satu hari. Penelitian ini menggunakan desain penelitian kualitatif. Melalui metode ini, penulis membuat gambaran secara sistematis mengenai permasalahan yang diangkat. Pendekatan kualitatif pada studi ini didasarkan atas pertimbangan bahwa penelitian memerlukan informasi yang mendalam (eksploratif) dari beberapa sumber. Teknik penelitian yang dilakukan adalah studi kasus. Hasil penelitian menunjukkan struktur rantai pasok dalam sistem logistik klaster sayuran. Struktur rantai pasok dikatakan berhasil apabila tercipta sistem yang efektif dan efisien sehingga memberikan manfaat pada seluruh pelaku dalam Klaster Sayuran.
\end{abstract}


Kata Kunci: Struktur rantai pasok, Klaster sayuran, Komoditas sayuran utama klaster, Sistem logistik pertanian

\section{PENDAHULUAN}

Komoditas sayuran merupakan salah satu produk hortikultura yang dikatagorikan bernilai tinggi bagi produsen dan konsumennya (Perdana, 2009). Produsen sayuran memiliki potensi untuk mendapatkan pendapatan yang tinggi dari usaha yang dilakukannya karena pada umumnya komoditas sayuran memiliki nilai ekonomi yang tinggi. Sedangkan bagi konsumen, produk sayuran memberikan manfaat yang baik untuk kesehatan sehingga menjadi salah satu alternatif diversifikasi pangan. Produk sayuran segar hasil dari impor memiliki kecenderungan harga yang lebih murah atau berimbang dengan produk lokal dan memiliki kualitas yang lebih baik sehingga produk impor memiliki peluang lebih besar untuk masuk ke pasar modern (Worldbank, 2004). Namun demikian, sebenarnya pasar terstruktur merupakan peluang yang baik bagi produsen lokal. Pasar terstruktur seperti jasa pangan, industri, pasar ekspor, dan supermarket merupakan alternatif pilihan untuk petani sayuran untuk dapat menghindari fluktuasi harga karena pasar tersebut mengadakan perjanjian mengenai harga terlebih dahulu baik formal maupun informal. Pada jalur pemasaran yang biasanya melalui banyak pihak, seringkali petani menghadapi ketidakpastian harga (Perdana \& Kusnandar, 2012).

Pasar terstruktur memberikan spesifikasi tertentu kepada produk-produk yang akan masuk, seperti spesifikasi kualitas juga pasokan yang kontinyu. Permintaan tersebut yang seringkali memberatkan petani sayuran lokal yang belum melakukan pengelolaan penanganan pasca panen dengan baik sehingga membuat sayuran yang telah dipanen tidak dapat terjaga kualitasnya seperti berkurangnya kesegaran dan penyusutan dalam jumlah karena pembusukan yang terlalu cepat (Perdana, 2009). Bahkan penyusutan hasil saat pasca panen dapat lebih dari $40 \%$. Hal tersebut akibat dari kurangnya pengetahuan petani mengenai perlakuan saat panen dan penyimpanan sementara, juga buruknya bahkan tidak adanya fasilitas penyimpanan dan penanganan pascapanen yang layak (Gebresenbet \& Bosana, 2012). Tingginya permintaan dari konsumen dalam rantai pasok sayuran meningkatkan kualitas sayuran yang berorientasi pasar global, hingga saat ini permintaan semakin meningkat baik dari dalam maupun luar negeri.

Pengembangan manajemen rantai pasok sayuran terdiri dari tiga level iterasi yaitu pengembangan manajemen rantai pasok inklusif, pengembangan layanan logistik pertanian di perdesaan dan pengembangan klaster agribisnis (Simatupang et al., 2013). Secara khusus, pengembangan klaster agribisnis merupakan keterkaitan petani, wirausaha lokal, perbankan dan layanan pengembangan bisnis pada suatu wilayah (Toma, 2009). Klaster agribisnis dapat dipandang sebagai konsentrasi geografis dari jejaring rantai pasok (DeWitt et al., 2006). Faktor penentu keberhasilan pengembangan klaster adalah keterkaitan antara lembaga bisnis, pemerintah, sistem keuangan serta lembaga pendidikan dan riset, komunitas, layanan pengembangan bisnis (Toma, 2009), serta permintaan menjadi faktor pendorong (Ditter, 2005; Reid et al., 2007; Perez-Meza \& Galdeano-Gomez, 2010).

Pengembangan klaster agribisnis sayuran bernilai tinggi akan meningkatkan kapasitas daya saing dan pendapatan produsen sayuran pada era perdagangan bebas. Faktor kunci pengembangan klaster agribisnis adalah orientasi pasar, inovasi teknologi, konsentrasi geografi, wiratani baru, dan pelibatan multi pemangku kepentingan (Nurfatiasari et al., 2014). Pengembangan sayuran bernilai tinggi Indonesia melalui pengembangan klaster agribisnis ditujukan untuk memenuhi pasar domestik, subtitusi impor dan peningkatan daya saing ekspor. Jenis sayuran bernilai tinggi yang perlu dikembangkan untuk memenuhi pasar domestik, subtitusi impor dan ekspor di antaranya adalah tomat, brokoli, kentang, wortel, dan buncis (ACDI/VOCA, 2011).

Salah satu Klaster Agribisnis sayuran bernilai tinggi di Kecamatan Pangalengan, Kabupaten Bandung, Jawa Barat berhasil menghasilkan produk yang diproduksi dari multi sumber tersebar dalam 8 Desa, multi komoditas berjumlah 16 komoditi di antaranya wortel baby, wortel regular, wortel holland, tomat tw, tomat beef, sawi, kentang reguler, kentang siomay, kentang rendang, paprika hijau, merah, kuning, oranye, white radish/lobak, kenya bean dan brokoli. 
Terdapat tujuh komoditas utama yang diproduksi dan dipenuhi permintaanya oleh kelompok tani Katata, komoditi utama tersebut di antaranya tomat tw, kentang reguler, paprika hijau, paprika merah, paprika kuning, paprika oranye dan white radish (lobak) (Tabel 1). Komoditas utama klaster sayuran Pangalengan dilatarbelakangi permintaan yang tinggi dari pasar terstruktur yaitu tomat tw dan kentang. Komoditi paprika hijau, merah, oranye dan kuning merupakan komoditi yang memiliki nilai jual tertinggi diantara sayuran lainnya, sedangkan white radish/lobak merupakan komoditas yang dipenuhi untuk pasar ekspor. Komoditas utama klaster sayuran memenuhi permintaan dari pasar khusus yang berbeda di antaranya pasar ekspor melalui eksportir, modern retail serta konsumen akhir sesuai dengan kesepakatan kontraktual antar pelaku.

Tabel 1. Multi pasar dan permintaan komoditas utama klaster sayuran bernilai tinggi.

\begin{tabular}{ll}
\hline \multicolumn{1}{c}{ Pasar terstruktur } & \multicolumn{1}{c}{ Komoditas (Grad A) } \\
\hline PT 'A' & White radish/lobak \\
\hline PT 'I' & Tomat tw \\
\hline Supermarket 'O' & Tomat tw \\
& Paprika oranye \\
\hline Supermarket 'U' & Kentang reguler \\
\hline & Paprika hijau \\
& Paprika merah \\
& Paprika kuning \\
& Paprika oranye \\
& Tomat tw \\
\hline
\end{tabular}

Klaster Sayuran Bernilai Tinggi Pangalengan memenuhi permintaan konsumen melalui Kelompok Tani Katata yang berjumlah 13 orang dan sub ordinasi petani lain yang merupakan mitra dan anggota yang berjumlah 125 anggota yang tersebar di 8 desa pada Kecamatan Pangalengan. Berdasarkan hasil observasi di lapangan, hal ini merupakan sebuah permasalahan dan tantangan pada sistem logistik dan distribusi karena produk tersebut harus memenuhi permintaan pasar terstruktur dengan minimnya tingkat pengembalian produk. Oleh Karen itu, sejak produk didistribusikan dari lahan menuju infrastruktur agribisnis perlu diterapkan metode yang tepat agar dapat menunjang efisiensi waktu serta biaya namun tetap memperhatikan kualitas produk. Proses pemenuhan permintaan dari multipasar yang berasal dari multisumber bukanlah persoalan yang mudah mengingat permintaan supply diharuskan secara berkelanjutan dengan kualitas dan kuantitas sesuai permintaan sehingga dibutuhkan kolaborasi antar pelaku rantai pasok klaster sayuran. Hal ini penting untuk dikembangkan bertujuan agar sistem bisnis berjalan berkelanjutan sehingga tercapainya kesejahteraan antar pelaku dan peluang tercapainya pasar potensial lainnya.

Penelitian ini bertujuan untuk menciptakan struktur rantai pasok pada sistem logistik Klaster Sayuran Bernilai Tinggi Pangalengan dan melakukan modifikasi antar pelaku dalam klaster sayuran bernilai tinggi (Gambar 1). Beberapa penelitian sebelumnya mengenai pengembangan model manajemen logistik produk segar dengan memperhatikan standard kualitas dan kuantitas sesuai permintaan pasar (Ahumada \& Villalobos, 2011), simulasi kejadian diskret (discrete event simulation) pada perancangan manajemen logistik di unit layanan logistik pertanian, serta pengembangan model sistem logistik yang optimal dilakukan pada Sub Terminal Agribisnis (STA) Mekar Mulya Kecamatan Pangalengan. Penelitian selanjutnya pada pengembangan model sistem logistik yang optimal dilakukan pada STA Mekar Mulya Kecamatan Pangalengan tahun 2014 melalui analisis manajemen logistik pada STA Mekar Mulya yang mengelola enam komoditas sayuran yaitu tomat beef, tomat tw, wortel, brokoli, kubis dan sawi yang berasal dari petani sekitar untuk tujuan pasar terstruktur (Nurfatiasari et al., 2014). 


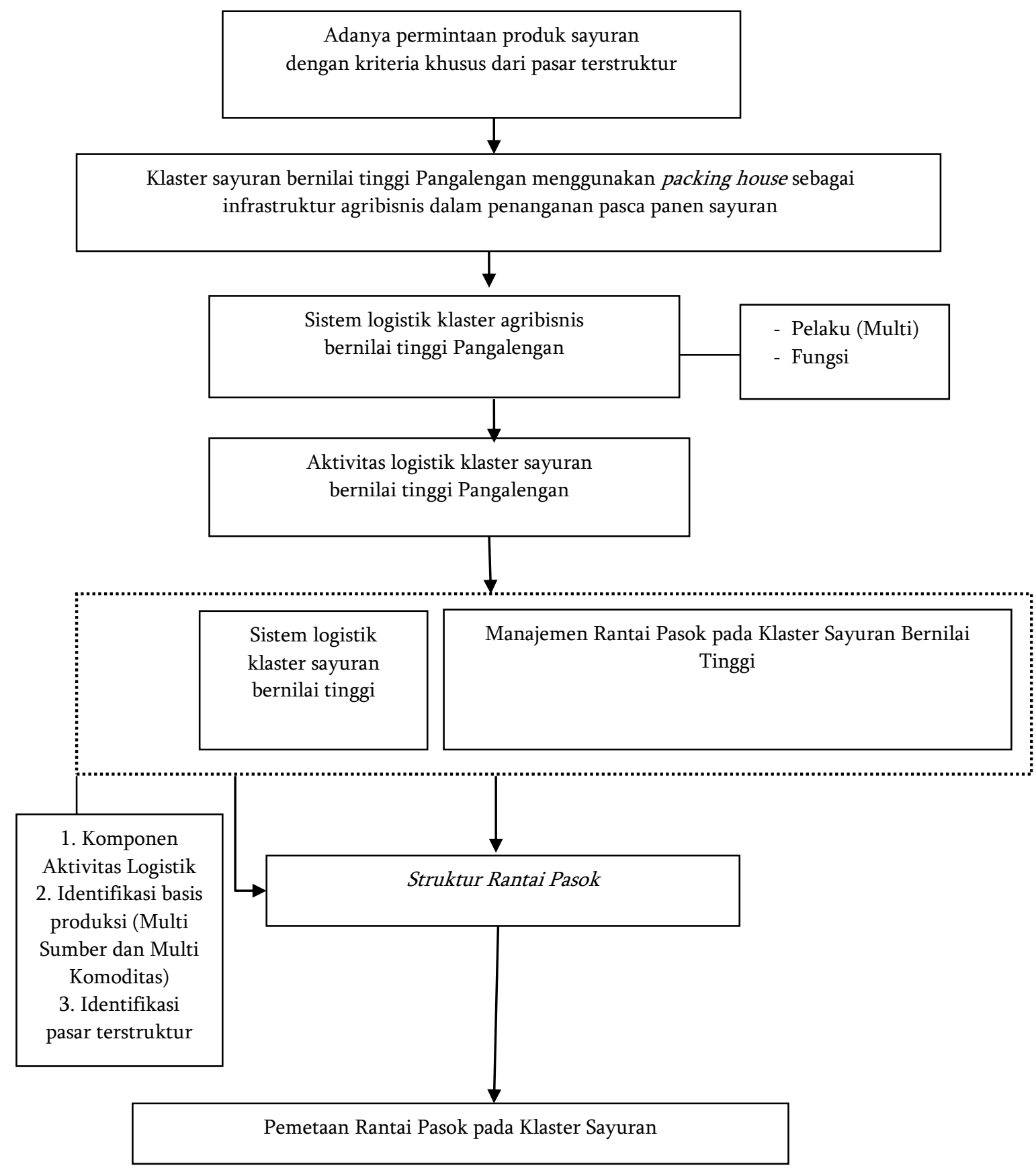

Gambar 1. Bagan alur pemikiran penciptaan struktur rantai pasok pada sistem logistik klaster sayuran bernilai tinggi. Keterangan: lingkup permasalahan.

\section{BAHAN DAN METODE}

Penelitian dilakukan dengan menggunakan desain penelitian kualitatif. Melalui metode ini, dibuat gambaran secara sistematis mengenai permasalahan yang diangkat. Pendekatan kualitatif pada studi ini didasarkan atas pertimbangan bahwa penelitian memerlukan informasi yang mendalam (eksploratif) dari beberapa sumber. Teknik penelitian yang dilakukan adalah studi kasus (case study). Penelitian studi kasus adalah pendekatan penelitian yang mengisyaratkan peneliti melakukan eksplorasi dan analisis secara intensif dan mendalam terhadap suatu fenomena dalam konteksnya dengan menggunakan data dari berbagai sumber (Thomas, 2011). Studi kasus dipilih karena melalui desain ini dapat dieksplorasi suatu fenomena dan dikumpulkan secara detail berbagai informasi yang dapat digunakan sesuai dengan prosedur pengumpulan data selama periode waktu tertentu. Desain penelitian yang dilakukan adalah kualitatif 
menggunakan teknik penelitian studi kasus dengan mengambil kasus pada klaster sayuran bernilai tinggi di Kecamatan Pangalengan, Kabupaten Bandung, Jawa Barat. Pada penelitian ini, desain kualitatif digunakan untuk mendeskripsikan aktivitas logistik secara terukur, selain itu dilakukan juga analisis keadaan sistem logistik yang sedang dilaksanakan sehingga dapat dirancang model sistem logistik dan rute pengangkutan hasil panen yang optimal melalui simulasi kejadian diskrit yang mengacu pada software Production modelar (ProModel) Corporation $4.2 \quad 2011$ sehingga mampu meningkatkan pendapatan petani.

\section{HASIL DAN PEMBAHASAN}

Gambaran Umum Klaster Sayuran Bernilai Tinggi Pangalengan dan Kelompok Tani Katata

Penelitian dilakukan di Klaster Sayuran

Bernilai Tinggi Pangalengan di Kecamatan Pangalengan, Kabupaten Bandung, Jawa Barat. Jarak dari kota Bandung sebagai Ibu Kota Propinsi Jawa Barat ke Pangalengan adalah $\pm 40 \mathrm{~km}$, sedangkan dari Kecamatan Soreang sebagai Ibu Kota Kabupaten Bandung adalah $\pm 31 \mathrm{~km}$. Kecamatan Pangalengan berbatasan dengan wilayah: Kecamatan Cimaung (Utara), Kecamatan Talegong (Selatan), Kecamatan Pacet dan Kecamatan Kertasari (Timur) dan Kecamatan Pasir jambu (Barat). Secara administratis, total luas 25.552.31 ha terbagi menjadi 13 desa yaitu (2.208,970 ha), Lamajang (4.016,10 ha), Margaluyu (860,200 ha), Margamekar (817,993 ha), Margamukti $(2.613,05$ ha), Margamulya $(1.294,14$ ha $)$, Pangelangan (589,946 ha), Pulosari (5.118,15 ha), Sukaluyu (1.748,200 ha), Sukamanah (668,040 ha), Tribaktimulya (449,909 ha), Wanasuka (4.555,97 ha), dan Warnasari (2.354,12 ha). Dengan demikian total luas Kecamatan Pangalengan adalah 27.294,77 ha (Profil Kecamatan Pangalengan, 2014). Profil Kelompok Tani Katata disajikan pada Tabel 2.

Tabel 2. Profil Kelompok Tani Katata.

\begin{tabular}{|c|c|c|c|c|c|c|}
\hline No. & Desa garapan & Mitra & Jumlah & Komoditas & $\begin{array}{l}\text { Luas } \\
\text { Lahan }\end{array}$ & $\begin{array}{c}\text { Jarak lahan ke } \\
\text { PH }\end{array}$ \\
\hline \multirow[t]{2}{*}{1.} & Marga Mekar & Katata Induk & 8 & Tomat tw, wortel, benih & & \\
\hline & & & & $\begin{array}{l}\text { kentang, benih wortel, kubis, } \\
\text { tomat beef, zuchini }\end{array}$ & 4 ha & $1 \mathrm{~km}$ \\
\hline 2. & Marga Mekar & Surya Tani & 7 & Kubis, tomat tw & 2 ha & $2 \mathrm{~km}$ \\
\hline \multirow[t]{2}{*}{3.} & Marga Mekar & Kramat Tani & 11 & $\begin{array}{l}\text { Benih kentang, wortel baby, } \\
\text { tomat tw, kentang, paprika }\end{array}$ & 7 ha & $2 \mathrm{~km}$ \\
\hline & Pulosari & & & & 5 ha & $3 \mathrm{~km}$ \\
\hline 4. & Marga Mekar & Tani Perkasa & 13 & Benih kentang, bibit wortel & 1 ha & $2 \mathrm{~km}$ \\
\hline 5. & Marga Mekar & $\begin{array}{l}\text { Perkasa } \\
\text { Gumilang }\end{array}$ & 7 & $\begin{array}{l}\text { Benih kentang, wortel baby, } \\
\text { tomat beef dan tw }\end{array}$ & 2 ha & $3 \mathrm{~km}$ \\
\hline 6. & Marga Mekar & $\begin{array}{l}\text { Dynamic } \\
\text { Farm }\end{array}$ & 10 & $\begin{array}{l}\text { Benih kentang, tomat tw, white } \\
\text { radish }\end{array}$ & 1,5 ha & $2 \mathrm{~km}$ \\
\hline \multirow[t]{2}{*}{7.} & Pangalengan & Kataji & 7 & $\begin{array}{l}\text { Tomat beef, wortel reguler dan } \\
\text { baby, tomat cherry }\end{array}$ & 3 ha & $6 \mathrm{~km}$ \\
\hline & Marga Mulya & & & Tomat cherry, tomat tw, brokoli & 2 ha & $7 \mathrm{~km}$ \\
\hline 8. & Pangalengan & Srijaya & 12 & $\begin{array}{l}\text { Tomat tw, tomat beef, wortel } \\
\text { baby dan reguler, kentang }\end{array}$ & 4 ha & $6 \mathrm{~km}$ \\
\hline 9. & Tribaktimulya & Mekarmulya & 13 & $\begin{array}{l}\text { Tomat tw, white radish, } \\
\text { kentang, wortel baby dan } \\
\text { reguler }\end{array}$ & $6 \mathrm{ha}$ & $15 \mathrm{~km}$ \\
\hline 10. & Margaluyu & Naratas & 11 & White radish, kubis & 3 ha & $6 \mathrm{~km}$ \\
\hline 11. & Warnasari & $\begin{array}{l}\text { Waluh } \\
\text { Sajagad }\end{array}$ & 10 & Labu siam, tomat tw, tomat beef & 2 ha & $6 \mathrm{~km}$ \\
\hline 12. & Marga Mekar & Raksa Buana & 8 & $\begin{array}{l}\text { Tomat tw, tomat beef, wortel } \\
\text { baby dan reguler }\end{array}$ & 1,5 ha & $2 \mathrm{~km}$ \\
\hline 13. & Sukamanah & Pintu Salam & 8 & Tomat tw, brokoli & 2 ha & $9 \mathrm{~km}$ \\
\hline \multicolumn{5}{|c|}{ Nilai Rata-rata luas lahan garapan = Jumlah luas lahan/jumlah anggota } & $\mathrm{N}=\frac{46}{13}$ & 3,5 ha \\
\hline
\end{tabular}




\section{Gambaran Umum Infrastruktur Agribisnis Klaster Sayuran}

Packing house merupakan infrastruktur dalam layanan logistik pertanian klaster sayuran bernilai tinggi yang terletak di wilayah Desa Marga Mekar, Kecamatan Pangalengan, Kabupaten Bandung. Packing house memiliki aktivitas dalam mengelola penanganan pasca panen 6 komoditas utama sayuran yaitu kentang reguler, tomat tw, paprika hijau, oranye, kuning, merah, sedangkan satu komoditas utama yaitu lobak (white radish) tidak mengalami penaganan pasca panen pada infrastruktur agribisnis. Beragam komoditas sayuran tersebut merupakan permintaan dari pasar terstruktur yaitu PT 'I', supermarket ' $U$ ', supermarket 'O' dan eksportir PT 'A' yang telah bermitra dengan Kelompok Tani Katata.

Untuk mendukung terorganisirnya aktivitas packing house, maka telah dibentuk struktur organisasi pengelolaan packing house. Terdapat lima bagian dalam pengelolaan packing house yaitu saprodi, teknologi, produksi, distribusi dan pasca panen. Pengelolalaan packing house masih terus didampingi oleh tim pendamping dari Universitas Padjadjaran yaitu Katata Padjadjaran Agro Logistik Indonesia (KAPALINDO). KAPALINDO merupakan jasa layanan logistik, mendampingi packing house dalam mengelola produksi, pemanfaatan teknologi, akses informasi, sistem budidaya, penanganan pasca panen, riset dan pengembangan dalam kegiatan pasca panen serta membangun kerjasama dengan pasar terstruktur. Struktur organisasi dalam packing house merupakan petani anggota dalam Kelompok Tani Katata.

\section{Manajemen Rantai Pasok pada Klaster Sayuran Bernilai Tinggi}

Anggota Katata memiliki aliran sayuran kepada Kelompok Tani Katata. Setelah melakukan proses pengolahan pasca panen pada infrastruktur agribisnis melalui Kelompok Tani Katata selanjutnya distribusi sayuran yang tertuju kepada pasar terstruktur PT 'I', Supermarket 'U', Supermarket 'O' serta pasar ekspor melalui $\mathrm{PT}$ 'A' sebelum sampai kepada konsumen akhir. Secara umum, pembahasan struktur rantai pasok klaster sayuran bernilai tinggi menjabarkan beberapa anggota rantai pasok beserta peranannya dalam rantai pasok sayuran pada klaster. Anggota rantai pasok sayuran pada klaster yang dimaksud adalah pelaku usaha serta beberapa stake holder (anggota rantai pendukung) terkait. Pelaku usaha atau anggota utama rantai pasok terdiri atas anggota Katata, kelompok tani Katata, pasar terstruktur PT 'I', Supermarket 'U', Supermarket 'O' serta pasar ekspor melalui PT 'A', sedangkan anggota rantai pendukung yaitu Bank Indonesia, Universitas Padjadjaran (KAPALINDO), Pemda Kabupaten Bandung serta Dinas Pertanian Kabupaten Bandung (Gambar 2).

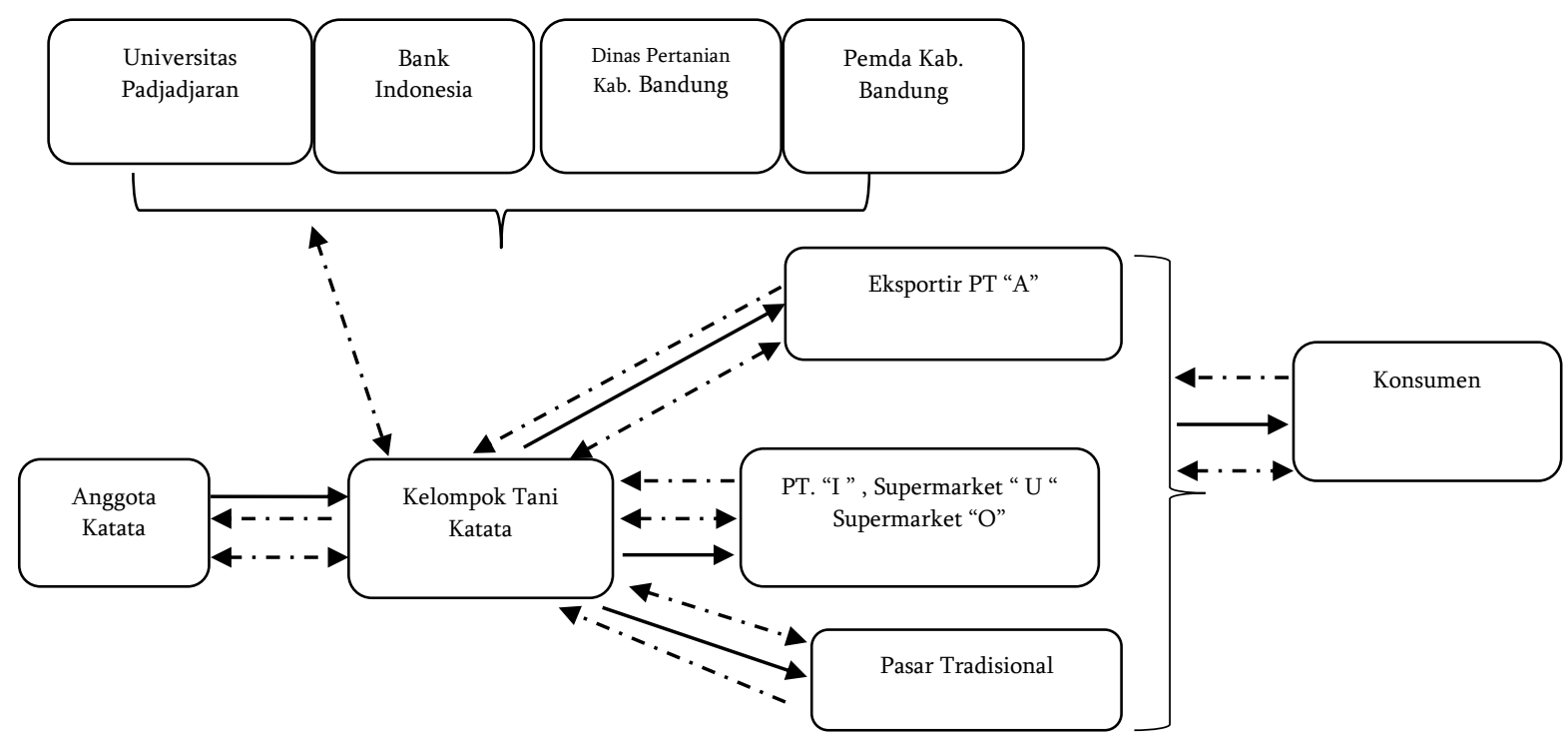

Gambar 2. Struktur rantai pasok Klaster Sayuran Bernilai Tinggi Pangalengan.

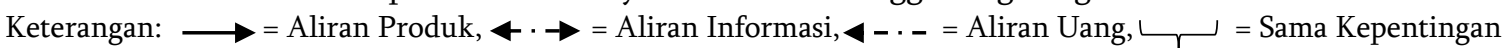




\section{Pemetaan Rantai Pasok Sayuran di Packing House pada Klaster Sayuran}

Packing house Katata merupakan infrastruktur agribisnis klaster sayuran bernilai tinggi telah menjalin kemitraan dengan Kelompok Tani Katata, pasar tersrtuktur dan pasar ekspor. Kemitraan kerja yang menjadikan packing house sebagai jasa layanan logistik pertanian. Bentuk kemitraan dengan Katata tidak melalui kontrak tertulis namun berdasarkan kepercayaan karena sifat infrastruktur bukan hanya sebagai penyalur kepada pasar terstruktur melainkan pemberi jasa logistik, jasa pengemasan sebelum komoditas sayuran dijemput maupun dikirimkan ke pasar terstruktur.

Terdapat dua jenis kontrak yang berlaku dalam rantai pasok sayuran pada infrastruktur agribisnis sayuran. Hubungan antara klaster sayuran Pangalengan dengan pasar ekspor PT 'A' yaitu kelompok tani dalam klaster sayuran menjalin kemitraan langsung sehingga jika terdapat masalah atau kesalahan dalam mengirimkan produk, hal tersebut menjadi tanggung jawab kelompok tani karena produk dikirim atas nama kelompok tani dan langsung melalui kelompok tani.
Oleh karena itu, kontrak antara packing house dan pasar ekspor PT 'A' berbeda dengan kontrak antara kelompok tani dan pasar ekspor PT 'A'. Kedua kontrak tersebut berisi mengenai harga yang disepakati, sistem pembayaran juga ketentuan jenis, jumlah dan periode pengiriman produk.

Kemitraan antara packing house dan pasar terstruktur PT 'I', Supermarket 'U', dan Supermarket 'O' juga melalui kontrak. Pada kontrak ini isinya berbeda dengan kontrak antara petani dengan pasar terstruktur tersebut. Kontrak tersebut berisi bahwa packing house bertanggung jawab kepada pengelolaan kualitas produk saat produksi, pengelolaan pasca panen hingga pengemasan selanjutnya distribusi ke PT 'I', Supermarket 'U', dan Supermarket 'O'. Oleh karena itu, petani yang menjadi produsen sayuran adalah tanggung jawab klaster sayuran bernilai tinggi. Kontrak berisi kesepakatan harga setelah komoditas menerima pengelolaan pasca panen dari packing house, sistem pembayaran, dan ketentuan permintaan sayuran.

Tabel 3. Spesifikasi komoditas klaster sayuran.

\begin{tabular}{|c|c|c|c|c|c|}
\hline Pasar terstruktur & $\begin{array}{c}\text { Komoditas } \\
\text { (Grad A) }\end{array}$ & Packing/buah & $\begin{array}{l}\text { Ukuran } \\
\text { (berat) }\end{array}$ & $\begin{array}{l}\text { Permintaan per } \\
\text { minggu }(\mathrm{kg})\end{array}$ & $\begin{array}{c}\text { Harga } \\
\text { (rupiah/kg) }\end{array}$ \\
\hline PT 'A' (Ekspor) & $\begin{array}{l}\text { White dadish } \\
\text { (lobak) }\end{array}$ & - & $400-700 \mathrm{~g}$ & 3000 & 2.500 \\
\hline PT 'I' & Tomat tw & $20 \mathrm{~kg} / \mathrm{pack}$ & $>125 \mathrm{~g} / \mathrm{buah}$ & 5000 & $5.000-8.000$ \\
\hline Supermarket 'O' & Tomat tw & 1 pack $=10 \mathrm{~kg}$ & $25 \mathrm{~g} / \mathrm{buah}$ & 500 & 8.500 \\
\hline \multirow[t]{9}{*}{ Supermarket 'U' } & Paprika oranye & 5 kg/pack & $200 \mathrm{~g} / \mathrm{buah}$ & 100 & 44.300 \\
\hline & $\begin{array}{l}\text { Kentang } \\
\text { reguler }\end{array}$ & $15 \mathrm{~kg} /$ pack & $\begin{array}{c}\text { 8-10 } \\
\text { buah/kg }\end{array}$ & 3000 & 11.000 \\
\hline & Paprika & $5 \mathrm{~kg} / \mathrm{pack}$ & $\begin{array}{l}\text { 150-200 } \\
\text { g/buah }\end{array}$ & 620 & - \\
\hline & Hijau & & & 100 & 24.900 \\
\hline & Merah & & & 160 & 31.500 \\
\hline & Kuning & & & 160 & 38.000 \\
\hline & Oranye & & & 200 & 44.300 \\
\hline & Tomat tw & $10 \mathrm{~kg} /$ pack & $\begin{array}{l}\text { 112-124 } \\
\text { g/buah }\end{array}$ & 500 & 8.500 \\
\hline & Total sayuran & & & 13.280 & \\
\hline
\end{tabular}


Kelompok Tani Katata dan anggota kelompok serta petani mitra bertanggung jawab dalam memasok sayuran on grade kepada pasar terstruktur. Anggota kelompok mendistribusikan sayuran ke Kelompok Tani Katata selanjutnya dilakukan proses pengolahan pasca panen pada infrastruktur agribisnis. Ketika terdapat produk sayuran yang tidak sesuai dengan spesifikasi permintaan pasar (off grade), maka sayuran tersebut dijual ke pasar tradisional. Pelaku yang terlibat dalam rantai pasok sayuran di packing house terdiri dari petani, packing house, Eksportir PT 'A', pasar terstruktur PT 'I', Supermarket 'U', supermarket 'O' dan pasar tradisional.
Infrastruktur agribisnis pada klaster sayuran bernilai tinggi mengelola pelayanan logistik yang terfokus pada komoditas sayuran unggulan yang diproduksi oleh Kelompok Tani Katata berdasarkan permintaan pasar terstruktur. Permintaan komoditas sayuran dari eksportir PT 'A' adalah white radish (lobak), permintaan dari PT 'I' adalah tomat tw. Permintaan supermarket 'O' adalah, tomat tw, paprika hijau, kuning, merah dan oranye. Permintaan supermarket 'U' adalah kentang reguler, paprika hijau, merah, kuning dan oranye, tomat tw. Setiap komoditas memiliki spesifikasi dan kriteria khusus dimana spesifikasi dan kuantitas ditentukan oleh pasar terstruktur (Tabel 3).

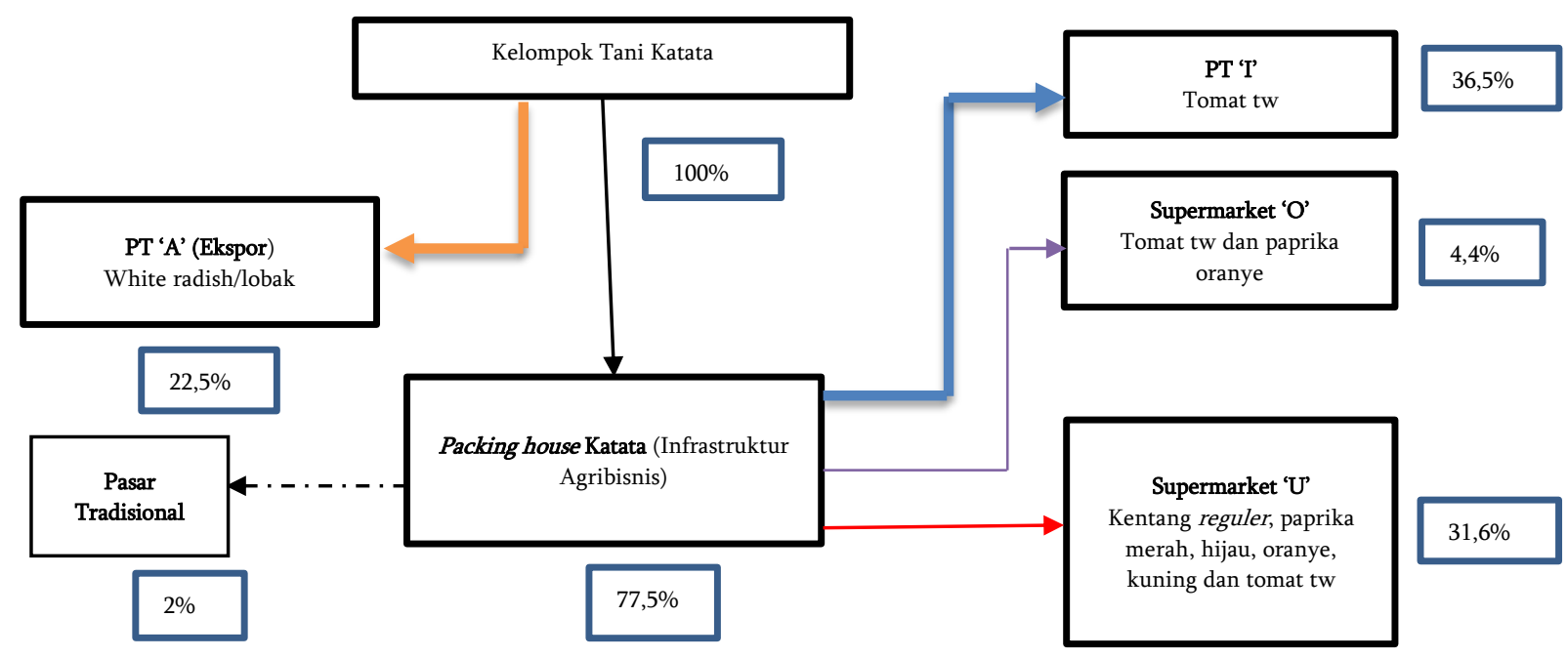

Gambar 3. Aliran barang (sayuran) pada Klaster Sayuran Bernilai Tinggi Pangalengan.

Keterangan: _- - - = produk reject. Angka dalam \% menunjukkan persentase distribusi.

Seluruh komoditas sayuran pada Tabel 3 diproduksi sesuai umur panen masing-masing komoditas, oleh karena itu pasar terstruktur melakukan permintaan sebelum masa tanam. Pada setiap panen dilakukan panen pilih agar proses sortasi dan grading pada packing house tidak terlalu lama. Setelah sayuran tersebut dipanen, infrastruktur agribisnis melakukan penjemputan sayuran menggunakan mobil pengangkut ke packing house Katata. Saat sayuran sampai di packing house, segera dilakukan penimbangan, sortasi, grading, pembersihan, pemotongan atau pencucian, sampai packing. Klaster sayuran bernilai tinggi melakukan pengemasan dengan brand Katata. Sayuran permintaan PT 'A' yaitu Lobak setelah diproses pada lahan selanjutnya produk dikembalikan kepada kelompok tani kemudian dijemput oleh PT 'A'. Proses Permintaan PT 'I', Supermarket ' $U$ ' dan Supermarket 'O' dipenuhi oleh kelompok Tani Katata selanjutnya dilakukan pengemasan pada packing house, kemudian dilakukan distribusi produk siap jual pada masing masing pasar terstruktur. Aliran sayuran dari lahan produksi hingga ke tangan konsumen dapat dilihat pada Gambar 3.

\section{SIMPULAN DAN SARAN}

\section{Simpulan}

1. Klaster sayuran telah berhasil melakukan akses bisnis terhadap pasar terstruktur. Namun demikian, sistem logistik aktual packing house dalam pemenuhan permintaan belum 
mencapai 100\%. Kinerja instrumen logistik pada packing house dipengaruhi oleh jumlah produk dalam proses, cara kerja stasiun logistik, dan tingkat permintaan pasar.

2. Struktur Rantai Pasok memengaruhi kinerja dan kolaborasi antar pelaku.

3. Pemetaan Rantai Pasok dapat menjaga hubungan antar pelaku serta mengurangi resiko.

\section{Saran}

1. Hubungan antar pelaku dalam klaster sayuran dapat dianalisis lebih jauh dengan waktu pengamatan yang lebih lama sehingga dapat dilihat dinamika dan konflik dalam organisasi.

2. Penelitian ini dibatasi hingga produk siap dikirim menuju pasar terstruktur. Dibutuhkan penelitian lebih lanjut dalam membangun layanan transportasi, pemilihan moda serta mempertahankan jaringan logistik Klaster Sayuran.

3. Peran logistik sangat besar dalam menciptakan produk sesuai permintaan. Keterlacakan produk serta sistem agribisnis pada basis produksi merupakan hal yang bisa diteliti lebih lanjut.

\section{DAFTAR PUSTAKA}

ACDINOCA. 2013. Agricultural Cooperative Development International/Volunteers in Overseas Cooperative Assistance. Vegetables for Ghana's vulnerable. Available online at: www.preventionweb.net (accessed 22 October 2014)

Ahumada, O and JR Villalobos. 2011. Operational model for planning the harvest and distribution of perishable agricultural products. Int. J. Production Economics. 133: 677-687.

DeWitt T, LC Guinipero and HL Melton. 2006. Clusters and supply chain management: The Amish experience. International Journal of Physical Distribution and Logistics Management. 26(4): 289-308.

Ditter, JG. 2005. Reforming the French wine industry: could cluster work? Cahiers du CEREN. 13: 39-54.

Gebresenbet, G and T Bosona. 2012. Logistics and supply chains in agriculture and food. in Pathways to Supply Chain Excellence, Dr.
Ales Groznik (Ed.), InTech, DOI: 10.5772/25907. Available from: http://www.intechopen.com/books/pathwa ys-to-supply-chain-excellence/logisticschains-in-food-and-agriculture-sector Accessed 9 November 2014.

Nurfatiasari, S, Kusnandar dan T Perdana. 2014. Logistics system development of vegetabel product for structured market: A case study of a packing house. Proceedings of $6^{\text {th }}$ International Conference on Operations and Supply Chain Management.

Perdana, T. 2009. Manajemen Rantai Pasokan Hortikultura untuk Memenuhi Pasar Ekspor. Lokakarya Manajemen Rantai Pasokan Hortikultura untuk Memenuhi Pasar Ekspor. 28 Desember 2009. Universitas Padjadjaran, Indonesia.

Perdana, $\mathrm{T}$ and Kusnandar. 2012. The Triple Helix Model for fruits and vegetabels supply chain management development involving small farmers in order to fulfill the global market demand: A case study in value chain center Universitas Padjadjaran. Procedia-Social and Behavioral Sciences. 52: 80-89.

Perez-Meza, JC and E Galdeano-Gomez. 2010. Agrifood cluster and transfer of technology in the Spanish vegetables exporting sector: The role of multinational enterprises. Agric Econ-Czech. 56 (12): 478-488.

ProModel Corporation. 2011. ProModel 2011 User Guide. ProModel Corporation.

Reid, N, MC Carroll and BW Smith. 2007. Critical Steps in the Cluster Building Process. Economic Development Journal. 6 (4): 4452.

Simatupang, MT, Y Handayati dan T Perdana. 2013. A new Collaborative Approach for Horticultural Supply Chain. Logistics and Supply Chain in Indonesia: Emerging Practices. School of Business and Management. Institut Teknologi Bandung.

Thomas, G. 2011. A typology for the case study in social science following a review of definition, discourse, and structure. Qualitative Inquiry. 17(6): 511521.

Toma, E. 2009. Agribusiness cluster - between theory and practice. Scientific Papers Management. Economic Engineering in Agriculture and Rural Development 9 (3): 205-210. 
WorldBank. 2004. Agicultural Trade Facilitation Study in Subsaharan Africa, Structure and Dynamics of the European Market for Horticulture Products and Opportunities for SSA Exporters. Available online at: http://search.worldbank.org/all?qterm=horti culture. Accessed 2 November 2014. 